Hydrogen-plasma-induced thermal donors in high resistivity $n$-type magnetic Czochralski-grown silicon

Y. L. Huang, E. Simoen, C. Claeys, J. M. Rafí, P. Clauws, R. Job, and W. R. Fahrner

Citation: Appl. Phys. Lett. 89, 031911 (2006); doi: 10.1063/1.2227076

View online: https://doi.org/10.1063/1.2227076

View Table of Contents: http://aip.scitation.org/toc/apl/89/3

Published by the American Institute of Physics

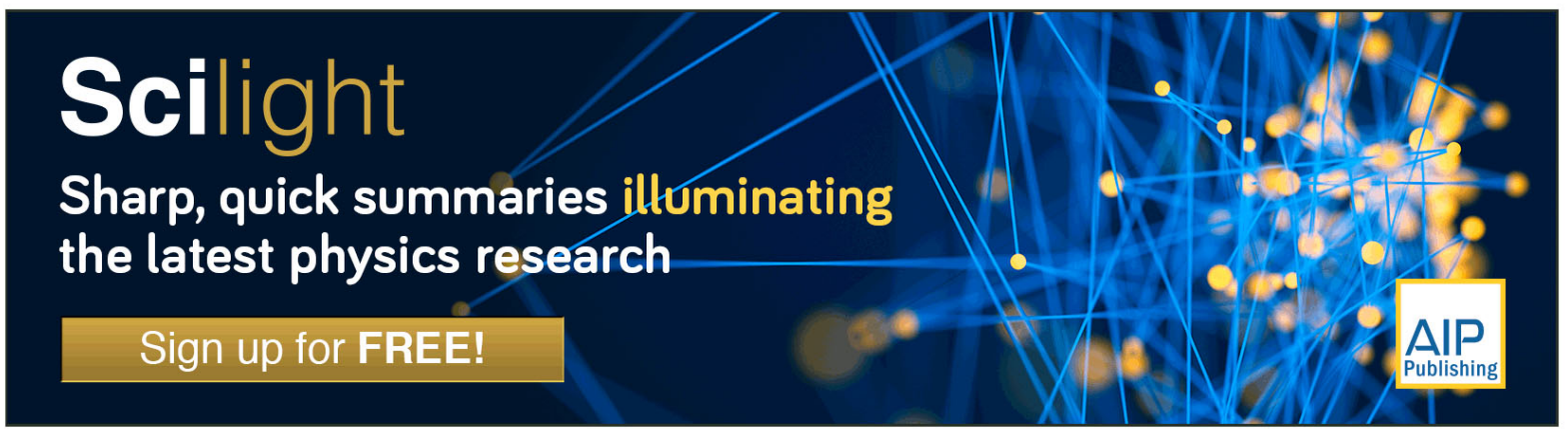




\title{
Hydrogen-plasma-induced thermal donors in high resistivity $n$-type magnetic Czochralski-grown silicon
}

\author{
Y. L. Huang ${ }^{a)}$ \\ Institut für Photovoltaik, Forschungszentrum Jülich, D-52425 Jülich, Germany \\ E. Simoen and C. Claeys \\ IMEC, B-3001 Leuven, Belgium \\ J. M. Rafí \\ Institut de Microelectrónica de Barcelona (CNM-CSIC), Campus UAB, 08193 Bellaterra, Spain \\ P. Clauws \\ Department of Solid-State Science, Ghent University, B-9000 Gent, Belgium \\ R. Job and W. R. Fahrner \\ Chair of Electronic Devices, University of Hagen, 58084 Hagen, Germany
}

(Received 3 April 2006; accepted 26 May 2006; published online 18 July 2006)

\begin{abstract}
In this work, the formation of donors in $n$-type high resistivity magnetic Czochralski-grown silicon wafers, directly exposed to a hydrogen plasma, is investigated by a combination of capacitance-voltage $(C-V)$ and deep level transient spectroscopy (DLTS) measurements. $C$ - $V$ analysis demonstrates diffusionlike concentration profiles close to the surface, pointing to the formation of hydrogen-related shallow donors in silicon during the hydrogenation. In addition, oxygen thermal donors are created during a subsequent annealing (20 min) performed at $350-450{ }^{\circ} \mathrm{C}$, as demonstrated by DLTS. It is shown that the hydrogen-related shallow donors are the dominant donors in as-hydrogenated samples, while hydrogen acts as a catalyst during the formation of oxygen thermal donors in the temperature range of $350-450{ }^{\circ} \mathrm{C}$. It is finally shown that the formation of both kinds of donors is Fermi-level dependent. (C) 2006 American Institute of Physics. [DOI: 10.1063/1.2227076]
\end{abstract}

It is well established that oxygen thermal donors (OTDs) are created in oxygen-rich silicon upon annealing at $300-500{ }^{\circ} \mathrm{C} .{ }^{1,2}$ The OTD formation is significantly enhanced if the annealing is done in a hydrogen plasma. ${ }^{3}$ Apart from the OTD centers, the creation of shallow thermal donors (STDs) in silicon due to plasma hydrogenation was also reported. $^{4-6}$ The diffusionlike spatial distribution of the excess free carriers suggests the involvement of hydrogen in the core structure of the STDs. These hydrogen-related STDs are hereafter labelled STDH. ${ }^{4-6}$ A combined theoretical and experimental study has pointed out that the $\mathrm{C}_{i} \mathrm{O}_{i} \mathrm{H}$ (interstitial-carbon-interstitial-oxygen-hydrogen) complex could be the core of the STDH center. ${ }^{7}$ From an electronnuclear double resonance study, it was derived that the STDH and OTD centers have a similar overall structure, except that they are single and double donors, respectively. ${ }^{8}$ Therefore, it was also proposed that the formation of a STDH center could be caused by the capture of one hydrogen atom (/ion) at an interstitial $(I)$ atom in the core structure of the OTD centers $\left(\mathrm{Si}-\mathrm{O}_{i}-\mathrm{I}-\mathrm{O}_{i}-\mathrm{Si}\right){ }^{9}$

Currently, high resistivity $(\mathrm{HR})(\geqslant 1 \mathrm{k} \Omega \mathrm{cm})$ magnetic Czochralski (MCz) silicon is of high interest for the development of radio-frequency $(\mathrm{rF})$ complementary metal-oxidesemiconductor (CMOS) and bipolar CMOS (BICMOS) technologies, since this material significantly lowers the highfrequency noise coupling through the substrate and other system parasitics. For these applications, the HR of the material must be preserved throughout device processing. Hence, the formation of the OTD and STDH centers at typi-

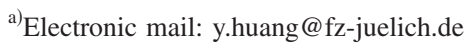

cal back-end temperatures between 300 and $500{ }^{\circ} \mathrm{C}$ should be suppressed. ${ }^{10}$ Therefore, the study of oxygen- and hydrogen-containing $\mathrm{MCz}$ silicon wafers at $300-500{ }^{\circ} \mathrm{C}$ is of relevant interest from both technological and scientific points of view.

In this letter, we report the formation of OTD and STDH centers in $n$-type $\mathrm{HR} \mathrm{MCz}$ silicon during hydrogen plasma exposure and subsequent annealing. The formation mechanism as well as the thermal evolution of these centers are discussed.

$n$-type $\mathrm{HR}(>500 \Omega \mathrm{cm}) \mathrm{MCz}$ silicon wafers from Okmetic are used as the starting material. The concentration of interstitial oxygen $\left(\left[\mathrm{O}_{i}\right]\right)$ is $(2-5) \times 10^{17} \mathrm{~cm}^{-3}$ as determined by Fourier transform infrared absorption spectroscopy. Hydrogenations are carried out by exposing the silicon wafers directly to hydrogen plasma at $270{ }^{\circ} \mathrm{C}$ for $2 \mathrm{~h} .{ }^{4}$ After the hydrogenation, isochronal annealing $(20 \mathrm{~min})$ is carried out up to $450{ }^{\circ} \mathrm{C}$. Ohmic contacts and Au Schottky barriers are fabricated for the capacitance-voltage $(C-V)$ measurements and deep level transient spectroscopy (DLTS), ${ }^{6}$ which is operated with a $1 \mathrm{~ms}$ pulse from a reverse bias $V_{R}(-10 \mathrm{~V})$ to various pulse voltages $V_{P}$ and a sampling period of $51.2 \mathrm{~ms}$. Capacitance-temperature $(C-T)$ curves are recorded at a $V_{R}$ of $-10 \mathrm{~V}$.

Concentration profiles of space charge are derived from the $C-V$ plots $(1 \mathrm{MHz})$ measured at room temperature, as described in Ref. 5. $C$ - $V$ measurements carried out at lower frequencies lead to very similar results, inferring that the series resistance effect is negligible. Figure 1 shows the profiles corresponding with $\mathrm{HR} \mathrm{MCz}$ silicon samples, which have received various treatments (hydrogenation and annealing). The as-received sample shows a fairly flat profile with 


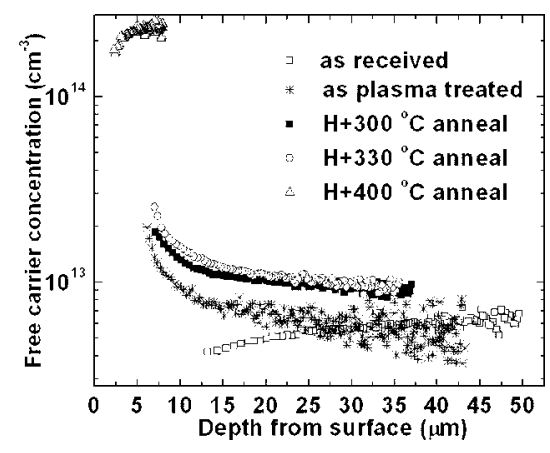

FIG. 1. Free carrier concentration profiles for $\mathrm{HR} \mathrm{MCz}$ silicon exposed to various treatments (hydrogen plasma exposure and posthydrogenation annealing) as well as for the as-received substrate.

an average concentration of about $5 \times 10^{12} \mathrm{~cm}^{-3}$. After hydrogenation, the free electron concentration of the subsurface layer increases evidently, indicating the formation of shallow donors. It can be seen that isochronal annealing at $300-450{ }^{\circ} \mathrm{C}$ leads to a further enhancement of the $n$-type doping concentration. Obviously, annealing at a higher temperature yields a higher concentration of the free carriers, at the same depth from the surface. For samples annealed at $400{ }^{\circ} \mathrm{C}$ or higher, the free electron concentration in the subsurface layer decreases when coming closer to the surface. This can be ascribed to an outdiffusion of hydrogen from the subsurface layer during the annealing. On the other hand, diffusionlike profiles are found up to the surface for the ashydrogenated sample and those annealed at lower temperatures, i.e., $300{ }^{\circ} \mathrm{C}$. The latter reflect, in fact, the indiffusion of hydrogen, ${ }^{4-6}$ suggesting a close correlation between hydrogen and the created shallow donors. It has been suggested in our previous work ${ }^{4-6}$ that the STDH and OTD centers are created in silicon during hydrogenation and subsequent annealing, respectively.

The OTD centers in $n$-type silicon can be detected by means of DLTS. Figure 2 shows the DLT spectra for various samples, recorded under a reverse bias $\left(V_{R}\right)$ of $-10 \mathrm{~V}$ and a pulse voltage $\left(V_{P}\right)$ of $0 \mathrm{~V}$. For the as-hydrogenated sample, four deep levels (labeled ME1-ME4) are detected with peak

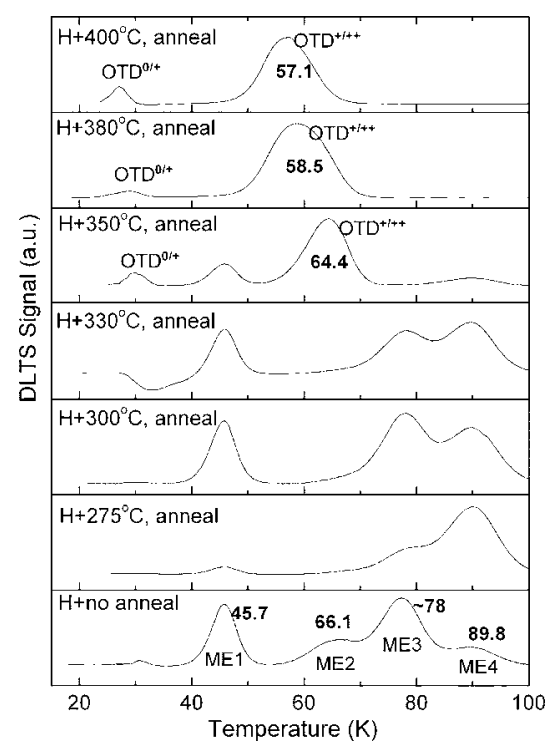

FIG. 2. DLT spectra for the samples hydrogenated for $2 \mathrm{~h}$ and subsequently annealed at various temperatures for $20 \mathrm{~min}$. The reverse bias and the pulse voltage are -10 and $0 \mathrm{~V}$, respectively. A filling pulse of $1 \mathrm{~ms}$ and a sampling period of $51.2 \mathrm{~ms}$ are applied. In some cases, the peak temperature $T_{P}$ is given.

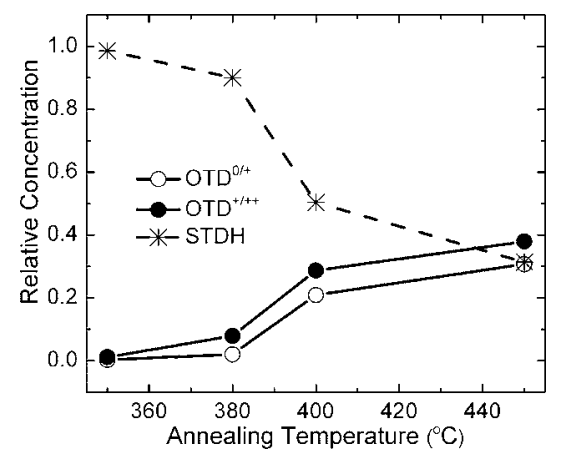

FIG. 3. Relative concentrations of excess electrons contributed by various donor levels plotted as a function of temperature of the isochronal annealing. All concentrations have been normalized to the total concentration of the excess electrons. The STDH centers are considered as single donors.

temperatures $\left(T_{P}\right)$ around $45.7,67.4,77.6$, and $89.6 \mathrm{~K}$. A detailed analysis on the electronic properties of these deep levels (ME1-ME4) will be reported elsewhere. It is also shown in Fig. 2 that OTD centers are created as the annealing is carried out at $350{ }^{\circ} \mathrm{C}$ or higher. For the sample annealed at $350{ }^{\circ} \mathrm{C}$, the single donor $\mathrm{OTD}^{0 /+}$ and double donor $\mathrm{OTD}^{+/++}$levels of the OTD centers are represented by the DLTS peaks at 30.1 and $64.4 \mathrm{~K}$, respectively. It is found that the DLTS peaks of the OTD centers shift clearly to lower temperatures with increasing annealing temperature. For instance, $T_{P}$ for the $\mathrm{OTD}^{+/++}$levels are $64.4,58.5$, and $57.1 \mathrm{~K}$ for the samples annealed at 350,380 , and $400{ }^{\circ} \mathrm{C}$, respectively. It is known that the OTD centers are cluster defects, and their average activation energy decreases with increasing cluster size. ${ }^{9}$ Hence, the shift of the DLTS peak to lower temperatures shown in Fig. 2 indicates a growth of the OTD clusters in size with increasing annealing temperature. Also, the $\mathrm{OTD}^{+/++}$peak for the samples annealed at 380 and $400{ }^{\circ} \mathrm{C}$ is much broader than that for the $350{ }^{\circ} \mathrm{C}$ anneal, giving additional evidence for the growth of the OTD centers. Last but not the least, since the OTDs are deep attractive centers in $n$-type silicon, a Poole-Frenkel shift of the DLTS peak maximum to lower temperatures will occur, as described, for example, in Ref. 5.

Furthermore, it is also observed that the contributions of the STDH and OTD centers to the $n$-type doping vary with the annealing temperature. Figure 3 shows the donor concentration for the different shallow-level centers normalized to the total concentration of excess carriers as a function of the annealing temperature. Here, we assume that each donor level contributes one electron to the excess electrons, i.e., STDH, OTD ${ }^{0 /+}$, and $\mathrm{OTD}^{+/++}$It can be seen in Fig. 3 that more than $90 \%$ excess electrons are contributed by the STDH centers at the annealing temperatures of 350 and $380{ }^{\circ} \mathrm{C}$. In comparison, the contribution from the STDH centers to the excess electrons is reduced to $50 \%$ and $31 \%$ for the 400 and $450{ }^{\circ} \mathrm{C}$ anneals, respectively. These results are in line with the information given by the $C-T$ plots.

As shown in Fig. 4, only one huge carrier freeze-out step is observed in the $C-T$ curve of the as-hydrogenated sample, which is ascribed to the ionization of the STDH centers and phosphorus donors. A similar $C-T$ curve is obtained for the hydrogenated material annealed at $350{ }^{\circ} \mathrm{C}$. In comparison, two considerable steps around 50 and $100 \mathrm{~K}$ appear in the $C$ - $T$ curve of the sample annealed at $450{ }^{\circ} \mathrm{C}$, which are attributed to the ionization of the $\mathrm{OTD}^{0 /+}$ and $\mathrm{OTD}^{+/++}$levels, respectively. Indeed, the $C-T$ result supports the fact shown in Fig. 3, i.e., the OTD centers become important only at 


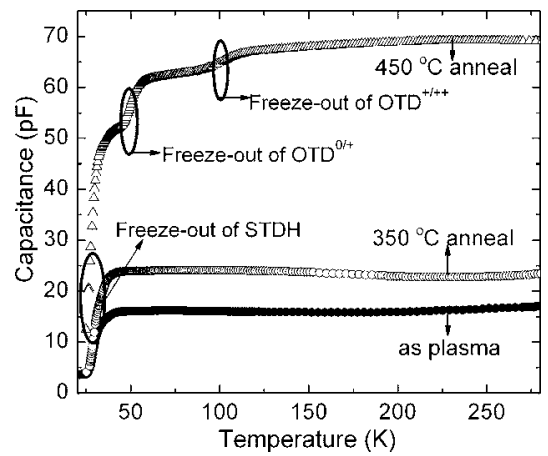

FIG. 4. $C$ - $T$ plots measured on the samples exposed to various treatments. A constant reverse bias of $-10 \mathrm{~V}$ is applied for all measurements.

annealing temperatures $\geqslant 400{ }^{\circ} \mathrm{C}$ due to the onset of hydrogen-catalyzed OTD formation, while the formation of the STDH centers is the dominant reaction for the short-term annealing $(20 \mathrm{~min})$ at temperatures $<400{ }^{\circ} \mathrm{C}$.

It has been reported in our previous work that a $p-n$ junction is created at a depth of $12.4 \mu \mathrm{m}$ in $p$-type $\mathrm{Cz}$ silicon after a hydrogen plasma exposure $\left(270{ }^{\circ} \mathrm{C}, 2 \mathrm{~h}\right) .{ }^{11}$ This $p$ - $n$ junction formation requires the introduction of excess electrons with a dose higher than the initial doping level, 1.2 $\times 10^{15} \mathrm{~cm}^{-3}$, in the surface-near region. By comparison, in $n$-type $\mathrm{MCz}$ silicon and at the same depth, the excess electron density is $3 \times 10^{12} \mathrm{~cm}^{-3}$ after the same hydrogenation, as seen in Fig. 1. This means that the introduction rate of free electrons in $n$-type $\mathrm{MCz}$ silicon is about three decades lower than that in $p$-type $\mathrm{Cz}$ silicon. This trend, i.e., a Fermi-level dependence, is in line with the very different introduction rates of excess electrons observed in $p$-type $\mathrm{Cz}$ silicon before and after the conversion of silicon from $p$ to $n$ type at a given depth. ${ }^{12}$ For instance, at a depth of $12.4 \mu \mathrm{m}$, the effective introduction rate of free electrons reduces from 6.0 $\times 10^{14}$ to $8.0 \times 10^{12} \mathrm{~cm}^{-3} / \mathrm{h}$ after the conversion of the conductivity type. Since no OTD centers are detected in ashydrogenated $\mathrm{MCz}$ silicon by DLTS, the high introduction rate of excess electrons in $p$-type silicon is ascribed to a high formation rate of the STDH centers.

It has been tentatively proposed that the $\mathrm{C}_{i} \mathrm{O}_{i} \mathrm{H}$ complexes correspond with the STDH centers and that the formation of one $\mathrm{C}_{i} \mathrm{O}_{i} \mathrm{H}$ complex is based on the capture of one hydrogen atom/ion by a $\mathrm{C}_{i} \mathrm{O}_{i}$ complex. ${ }^{4} \mathrm{~A}$ higher STDH formation rate means a higher possibility for a hydrogen atom (/ion) to be trapped by a $\mathrm{C}_{i} \mathrm{O}_{i}$ complex. The $\mathrm{C}_{i} \mathrm{O}_{i}$ complex can take different charge states. On the other hand, hydrogen is stable in its positive charge state in $p$-type silicon and in a neutral or negative charge state in $n$-type silicon. ${ }^{13}$ Since the STDH formation rate in $p$-type silicon is found to be higher than in $n$-type silicon, it is reasonable to speculate that the $\mathrm{C}_{i} \mathrm{O}_{i}$ complex prefers to take the negative charge state. Moreover, a possible role of the introduction rate of hydrogen during the plasma exposure in the STDH formation rate cannot be ruled out. Given the higher diffusivity for the positively charged hydrogen compared with $\mathrm{H}^{0},{ }^{13}$ a higher dose of hydrogen at a given depth can be reached in $p$-type $\mathrm{Cz}$ silicon than in $n$-type $\mathrm{HR} \mathrm{MCz}$ silicon after the same hydrogenation. In turn, significantly different STDH concentrations are observed in as-plasma-treated $p$ - and $n$-type silicon.

Similar to the STDH centers, our results reveal that the formation of the OTD centers is also Fermi-level dependent.
As shown in Fig. 3, the concentration of the OTD centers is very low compared to that of the STDH centers for the hydrogenated $n$-type $\mathrm{MCz}$ sample annealed at temperatures lower than $400{ }^{\circ} \mathrm{C}$. In comparison, photothermal ionization spectroscopy ${ }^{12}$ reveals the formation of a considerable amount of OTD centers in as-hydrogenated $p$-type $\mathrm{Cz}$ silicon. This observation can be well explained by a recent firstprinciples calculation. ${ }^{14}$ According to this calculation, the creation of the OTD centers found in our as-hydrogenated $p$-type silicon can be attributed to a H-catalyzed transformation from an electrically inactive staggered oxygen chain to an active oxygen ring (OTD configuration) with a negligible barrier. In $n$-type silicon, negative hydrogen $\left(\mathrm{H}^{-}\right)$is trapped at a small oxygen cluster with a binding energy of $0.45 \mathrm{eV}$ rather than transforming chains directly into rings. An electron can be emitted after the binding of $\mathrm{H}^{-}$to the oxygen cluster, transforming the complex to the neutral state, which in turn transforms the cluster to an active ring. The activation energy for this process is $1.4 \mathrm{eV}$ in $n$-type silicon; therefore, the OTD formation in $n$-type silicon is only active for annealing temperatures in the range of $350-450{ }^{\circ} \mathrm{C}$, cf. Fig. 2 .

In summary, STDH centers are created in $n$-type HR $\mathrm{MCz}$ silicon via a low temperature hydrogen plasma. hydrogen-catalyzed OTD formation is activated in hydrogenated silicon at $350-450{ }^{\circ} \mathrm{C}$. In the hydrogenated samples annealed at a temperature lower than $400{ }^{\circ} \mathrm{C}$, the STDH centers are the dominant shallow donors. The concentration of the OTD centers becomes comparable to that of the STDH centers as the annealing is carried out at $400-450{ }^{\circ} \mathrm{C}$. Both the STDH formation and the hydrogen-catalyzed OTD formation are Fermi-level dependent. The evident changes in the doping level due to the formation of the STDH and OTD centers suggest that serious care should be taken when using $\mathrm{HR} \mathrm{MCz}$ substrates for the applications mentioned above.

The (German Academic Exchange Service) DAAD is sincerely acknowledged by one of the authors (Y.L.H.) for the award of Ph.D. scholarship.

${ }^{1}$ C. S. Fuller, J. A. Ditzenberger, N. B. Hannay, and E. Buehler, Phys. Rev. 96, 833 (1954).

${ }^{2}$ F. Shimura, Oxygen in Silicon (Academic, San Diego, 1994).

${ }^{3}$ R. C. Newman, J. H. Tucker, A. R. Brown, and S. A. McQuaid, J. Appl. Phys. 70, 3061 (1991).

${ }^{4}$ Y. L. Huang, E. Simoen, C. Claeys, R. Job, Y. Ma, W. Düngen, W. R. Fahrner, J. Versluys, and P. Clauws, Solid State Phenom. 108-109, 547 (2005).

${ }^{5}$ J. M. Rafi, E. Simoen, C. Claeys, Y. L. Huang, A. G. Ulyashin, R. Job, J. Versluys, P. Clauws, M. Lozano, and F. Campabadal, J. Electrochem. Soc. 152, 16 (2005).

${ }^{6}$ E. Simoen, C. Claeys, R. Job, A. G. Ulyashin, W. R. Fahrner, O. De Gryse, and P. Clauws, Appl. Phys. Lett. 81, 1842 (2002).

${ }^{7}$ J. Coutinho, R. Jones, P. R. Briddon, S. Öberg, L. I. Murin, V. P. Markevich, and J. L. Lindström, Phys. Rev. B 65, 014109 (2002).

${ }^{8}$ T. Gregorkiewicz, H. H. P. Th. Beckman, and C. A. J. Ammerlaan, Phys. Rev. B 38, 3998 (1988).

${ }^{9}$ R. C. Newman, J. Phys.: Condens. Matter 12, R335 (2000).

${ }^{10}$ T. Abe and W. Qu, ECS PV 2000, 17, 491.

${ }^{11}$ Y. L. Huang, Y. Ma, R. Job, and A. G. Ulyashin, J. Appl. Phys. 96, 7080 (2004).

${ }^{12}$ Y. L. Huang, J. Lauwaert, E. Simoen, C. Claeys, P. Clauws, R. Job, and W. R. Fahrner, J. Appl. Phys. (submitted).

${ }^{13}$ S. J. Pearton, J. W. Corbett, and T. S. Shi, Appl. Phys. A: Solids Surf. 43, 153 (1987).

${ }^{14}$ L. Tsetseris, S. Wang, and S. T. Pantelides, Appl. Phys. Lett. 88, 051916 (2006). 